\title{
La discapacidad en el capitalismo industrial e informacional: aportes desde el materialismo cognitivo
}

\author{
Disability in industrial and informational capitalism: \\ Contributions from cognitive materialism
}

\begin{abstract}
Resumen
Este artículo aspira a realizar una contribución teórica preliminar para pensar la discapacidad mediante dos objetivos. Por un lado, ofrecer un abordaje que integre, de manera sistémica y sin reduccionismos, los aspectos biológicos, subjetivos, intersubjetivos y objetivos que configuran la discapacidad, a través de la propuesta del materialismo cognitivo. Por otro y en base a lo anterior, introducir la historicidad de tal configuración, indagando las diferencias y similitudes que presenta la discapacidad entre las etapas industrial e informacional del capitalismo. En términos metodológicos, junto con el material teórico y la literatura previa, se utilizan fuentes secundarias cualitativas y cuantitativas.
\end{abstract}

\section{Palabras clave}

Discapacidad, capitalismo, materialismo cognitivo, capitalismo industrial, capitalismo informacional, modelo social de la discapacidad.

\begin{abstract}
This article aims to make a preliminary theoretical contribution regarding disability through pursuing two objectives. On the one hand, it intends to offer an approach that integrates, in a systemic way and avoiding reductionisms, the biological, subjective, intersubjective and objective levels that configure disability, relying on the theoretical framework of cognitive materialism. On the other, we aim to introduce the historicity of such configuration, investigating the differences and similarities that disability presents between the industrial and informational stages of capitalism. In methodological terms, along with theoretical insight and previous literature, qualitative and quantitative secondary sources are used.
\end{abstract}

\section{Keywords}

Disability, capitalism, cognitive materialism, industrial capitalism, informational capitalism, social model of the disability.

\section{Mariano Zukerfeld \\ $<$ marianozukerfeld@gmail.com>}

Universidad Maimónides (UMAI) · Consejo Nacional de Investigaciones Científicas y Técnicas de Argentina (CONICET). Argentina

\section{Mauro Alejandro Soto \\ $<$ maurosotoal@gmail.com>}

Universidad Nacional de Salta (UNSA) - Consejo Nacional de Investigaciones Científicas y Técnicas de Argentina (CONICET). Argentina

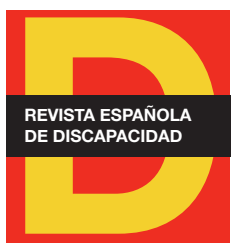

Para citar:

Zukerfeld, M. y Soto, M. A. (2020). "La discapacidad en el capitalismo industrial e informacional: aportes desde el materialismo cognitivo". Revista Española de Discapacidad, 8(2), pp. 57-83.

Doi: <https://doi.org/10.5569/23405104.08.02.03>

Fecha de recepción: 15-06-2020 Fecha de aceptación: 17-11-2020 


\section{Introducción'}

Este artículo aspira a realizar una contribución teórica para pensar la discapacidad proponiéndose dos objetivos relacionados pero distinguibles. Por un lado, presentar un abordaje que integre, de manera sistémica y sin reduccionismos, los aspectos biológicos, subjetivos, intersubjetivos y objetivos que configuran la discapacidad. Por otro, introducir la historicidad de tal configuración, indagando las diferencias y similitudes que presenta la discapacidad entre las etapas industrial e informacional del capitalismo².

En efecto, durante buena parte de la modernidad y particularmente en las sociedades capitalistas industriales, los abordajes de la discapacidad han enfatizado la dimensión biológica, reduciéndola a anomalías de ese orden respecto de ciertos valores tenidos por normales. De manera contrastante y como es bien conocido, en las últimas décadas la literatura especializada ha enfatizado el rol decisivo del nivel social o intersubjetivo, principalmente a través del modelo social de la discapacidad (Oliver, 1998; Palacios y Romañach, 2006; Palacios, 2008). Aunque estos abordajes indudablemente representan un progreso crucial, no siempre delimitan qué incluye (y qué no) el nivel social o intersubjetivo ni necesariamente lo hacen dialogar con otros niveles. En ese contexto podemos precisar el primer objetivo. En este artículo intentamos contribuir con las perspectivas que privilegian el nivel intersubjetivo, pero con algunos agregados teóricos: 1. La desagregación del nivel intersubjetivo en cinco dimensiones, para intentar evitar que la noción de "lo social" resulte muy genérica o etérea. 2. La reubicación del nivel biológico, que no debe silenciarse, sino integrarse y resignificarse. 3. El agregado del nivel subjetivo (o individual) que, al igual que los demás, dialoga con otros y no debe ser colapsado o negado (Zardel Jacobo, 2016). 4. El añadido del nivel objetivo: que refiere a los entes que creados por humanos existen por fuera de ellos: las tecnologías y la información.

Este enfoque surge de utilizar algunas categorías de la propuesta del materialismo cognitivo (Zukerfeld, 2017 que informa lo que sigue). En esta perspectiva, los niveles mencionados se nombran como tipos de conocimientos, entendiendo al conocimiento como el ente que junto con la materia/energía, compone todas las formas del ser. Sin embargo, el conocimiento sólo existe como forma emergente de la materia/ energía. Es decir, sólo existe sobre algún soporte material en el que se asienta. Lejos de ser inmaterial, son sus formas de existencia material, el soporte en el que existe, las que le confieren a cierto conocimiento propiedades económicas, jurídicas, etc., divergentes. Por ejemplo, que la idea de rueda (conocimiento) exista subjetivamente como representación mental individual, como objetivación en un artefacto determinado o como codificación en un texto (tres soportes diversos), confiere a ese conocimiento posibilidades muy disímiles de, por caso, difundirse, ser considerado eficaz o caer en el olvido. Es por ello que utilizamos a los soportes como línea divisoria para conformar una tipología de los conocimientos materialista. Pero ¿cuáles son los tipos de conocimiento en función de sus soportes? Hay cuatro tipos de conocimiento: de soporte biológico (CSB), de soporte subjetivo (CSS), de soporte intersubjetivo (CSI) y de soporte objetivo (CSO).

\footnotetext{
1. Este trabajo se origina en el trabajo conjunto entre los autores vinculado con la beca doctoral de CONICET del Lic. Soto dirigida por el Dr. Zukerfeld.

2. Aquí entendemos, como los autores que sustentan el enfoque del capitalismo cognitivo (ej. Boutang, 2011), que el capitalismo incluye pero excede la dimensión económica para abarcar a la totalidad social que habitamos.
} 
En las próximas secciones caracterizaremos más detalladamente cada uno de estos tipos. Ahora bien, cuando se caracteriza un período, institución o cualquier otra totalidad en función de los cuatro tipos de conocimientos se produce una configuración material cognitiva de esa totalidad.

Se trata, no obstante, de una totalidad dialéctica, en la que se producen tensiones, mayores o menores, entre los distintos tipos de conocimientos. Por eso, la configuración material cognitiva, que en sí misma es estática y registra stocks, debe complementarse con el análisis de las relaciones dinámicas entre las diversas formas de conocimientos. Para ello, el concepto principal es el de traducción. La traducción es una transformación de una forma de conocimiento en otra: por ejemplo, son traducciones el pasaje desde una idea individual a un texto, del texto a una creencia colectiva, desde allí a una individualidad. Cada traducción implica cierto grado de traición; el conocimiento original y el traducido no son completamente equivalentes.

Pasemos ahora a precisar el segundo objetivo. Varios trabajos han situado de manera clara y precisa la relación entre discapacidad y capitalismo (Joly, 2007; Oliver, 1990; Ferrante, 2015, entre otros). Así, no sólo se ha notado que hay una construcción social de la discapacidad, sino que tal construcción está asociada con un tipo de sociedad muy particular: la capitalista. Sin embargo, no son frecuentes las indagaciones acerca de la historicidad de la relación entre discapacidad y capitalismo. En otras palabras ¿los cambios de etapa dentro del capitalismo están relacionados con transformaciones en la relación entre capitalismo y discapacidad? Más precisamente ¿en qué medida la discapacidad en el capitalismo industrial es distinta de la discapacidad en el capitalismo informacional? Esta pregunta supone la asunción teórica de que el capitalismo puede dividirse provechosamente en etapas, específicamente en tres: el capitalismo mercantil (desde mediados del siglo XV a fines del XVIII), capitalismo industrial (fines del siglo XVIII hasta la década de 1970) y capitalismo cognitivo o informacional, hasta el presente (Boutang, 2011; Vercellone, 2012; Castells, 1996; Fuchs, 2010). En las secciones 2 a 5 se presentan los aspectos del capitalismo industrial e informacional que son relevantes para dar cuenta de la configuración de la discapacidad en cada etapa.

En términos metodológicos este trabajo combina: I. Fuentes teóricas sobre el capitalismo informacional, el materialismo cognitivo y diversos enfoques sobre la discapacidad; II. Ejemplos cualitativos de situaciones específicas tomados de la literatura para ilustrar tendencias; III. Revisión de normativas y páginas de redes y organizaciones, IV. Fuentes estadísticas sobre las que, en algunos casos, hemos producido elaboraciones propias.

El artículo está organizado del siguiente modo. Esta introducción es la primera sección. Las secciones 2, 3,4 y 5 tienen una estructura similar y cada una de ellas presenta un tipo de conocimiento en base a sus soportes. Primero se explica de forma genérica el tipo de conocimiento en cuestión -biológico, subjetivo, intersubjetivo y objetivo- y se presentan sus variedades. Luego se establecen contrastes entre sus características generales en el capitalismo industrial e informacional. Y a partir de allí el grueso de cada sección se dedica a caracterizar a la discapacidad respecto de cada tipo de conocimientos, analizando allí donde es posible el contraste que en este aspecto ofrecen el capitalismo industrial y el informacional. Finalmente, la sección 6 presenta las conclusiones del recorrido emprendido. 


\section{Conocimientos de soporte biológico}

Los conocimientos de soporte biológico (CSB) consisten en los flujos de datos codificados en términos genéticos, nerviosos o endocrinológicos en todos los seres vivos. Distinguimos entre los flujos naturales $u$ orgánicos (como la información genética que porta una semilla proveniente de un fruto natural) y los posorgánicos (como la información de una semilla surgida de la manipulación de la ingeniería genética).

En términos históricos, resulta claro que en el capitalismo industrial se produce un gran desarrollo de las posibilidades de traducir CSB a conocimientos subjetivos (de médicos y otros especialistas).

En este sentido, aparece en la literatura médica por primera vez un amplio espectro de condiciones médicas que le dan origen a algunas deficiencias y que pueden observarse al indagar en la historia de los desarrollos teóricos y técnicos en la anatomía, fisiología, traumatología, neurología, oftalmología, etc.

Por ejemplo, en el caso de la oftalmología, los numerosos estudios realizados por esta disciplina durante el siglo XIX identificaron diversas alteraciones o enfermedades oculares que daban origen a la ceguera. Estos son los casos del glaucoma por aumento de la presión intraocular, las cataratas producto de malformaciones en la córnea, el desprendimiento de retina, la retinosis pigmentaria, etc. (Río, 2017).

De un modo similar durante el mismo periodo, la neurología realizaría diagnósticos de ciertas alteraciones del lenguaje, limitaciones en los movimientos corporales o cambios del comportamiento, identificándolas con lesiones nerviosas o cerebrales (Muci Mendoza, 2007).

Pero la modalidad más radical de intervención durante el capitalismo industrial sobre el nivel de los conocimientos biológicos es la de la eugenesia totalitaria: no solo implicó mecanismos para el bloqueo de la transmisión de los códigos genéticos de las personas con discapacidad (un tipo de CSB) por medio de la prohibición del matrimonio y la inmigración, y la esterilización forzosa, sino también la eliminación de sus cuerpos, a través de su exterminio en masa (en el caso de Europa durante la Segunda Guerra Mundial).

En efecto, los CSB, fueron el eje del abordaje dominante de las personas con discapacidad durante el capitalismo industrial de la mano de las ciencias médicas y biológicas. Evidentemente, no se trata de un abordaje neutral o aséptico de los CSB - cosa que no existe en ningún caso-, sino cargado de los valores del período. De este modo, se configuró un reduccionismo biológico en el que la discapacidad era reconocida o intervenida como enfermedad, trauma, lesiones o condiciones de salud que ocurrían y afectaban el funcionamiento en el cuerpo de un individuo.

En el capitalismo informacional los CSB están signados por al menos dos procesos. Por un lado, los avances de la genética (la decodificación y traducción del lenguaje del ADN), inseparables del uso de tecnologías digitales para su sistematización y mercantilización. Por otro, la ingeniería genética, es decir, la creación de formas de información posorgánica y, de modo más general, la posibilidad de intervención de los cuerpos en el nivel biológico. 
Respecto de la expresión de estas tendencias en la discapacidad, mencionamos dos ejemplos:

Por un lado, la lectura y potencial intervención en relación a los rasgos genéticos de un feto antes de nacer (aplicados tanto en fecundación natural como in vitro). Como veremos más abajo estas operaciones sobre los CSB están ligadas a axiologías y formas de reconocimiento³.

Por otro lado, el desarrollo de prótesis físicas y sensoriales que funcionan utilizando y comunicando diversos CSB posorgánicos. Por ejemplo, los implantes cocleares que consisten en transductores que transforman las señales sonoras en señales eléctricas que estimulan el nervio auditivo (es decir, flujos biológicos nerviosos), contribuyendo a adquirir o recuperar la audición, en algunos casos ${ }^{4}$.

Es importante insistir en que los CSB biológicos no son en modo alguno el elemento definitorio de la discapacidad (como lo prescribía el modelo médico, ver CSI axiológicos), pero no por ello debemos negar la existencia de ciertas características biológicas que configuran lo que el modelo social (ídem) denomina deficiencias (impairments). Así, es importante considerar pero a la vez distinguir claramente este aspecto biológico acotado, de las construcciones subjetivas, intersubjetivas (especialmente asociadas a valores como la normalidad, la enfermedad, etc.) y tecnológicas que configuran la discapacidad. Hecha esta distinción, resulta útil partir de algunos datos relativos a la presencia de las deficiencias.

De acuerdo a datos de la Organización Mundial de la Salud de 2010 (OMS, 2011), alrededor de 1000 millones de personas alrededor del mundo vivían con deficiencias, lo que representaba cerca de un $15 \%$ de la población mundial. Este dato indica que estas deficiencias están en el capitalismo informacional en franco ascenso, dado que en 1970 afectaban a un $10 \%$ de la población mundial. El incremento, siempre de acuerdo a la OMS, se debe a dos razones: por un lado, el envejecimiento de la población (con la edad aumenta el riesgo de impedimentos físicos y mentales). Por otro lado, el incremento global de las enfermedades crónicas (diabetes, enfermedades cardiovasculares y trastornos mentales). Este incremento es un elemento material que colabora parcialmente para comprender la presión sobre los conocimientos intersubjetivos y tecnológicos para transformar las dinámicas sociales excluyentes y discapacitantes, como veremos más abajo.

\section{Conocimientos de soporte subjetivo}

Los conocimientos de soporte subjetivo (CSS) son aquellos conocimientos en los que el soporte es la mente individual. La distinción más relevante entre tipos de CSS es entre los implícitos (se activan de manera inconsciente y no intencional) y explícitos (a los que podemos acceder mediante una recolección consciente de recuerdos).

3. Así, algunas organizaciones del colectivo en Europa señalan que los exámenes genéticos y prenatales estarían siendo usados para limitar, restringir o impedir el nacimiento de personas con discapacidad (López Mainieri, 2012) Y que la legislación sobre las prácticas del aborto que le dan sustento, en el caso español, es contraria a los principios de la Convención (Palacios, 2010).

4. En cuanto a su funcionamiento, por medio de un micrófono, recoge los sonidos externos; luego un procesador escoge aquellos relevantes para la escucha verbal y los envía en forma de señales eléctricas a unos electrodos que son colocados dentro del oído interno, en la cóclea, es de allí que obtiene su denominación. Por último, los electrodos estimulan las células que permanecen activas, las cuales envían la señal eléctrica por medio del nervio auditivo al cerebro que reconstruye el estímulo sonoro (Morales, 2006). 
De manera general, el capitalismo industrial se caracteriza en este aspecto por la masificación de la construcción de conocimientos subjetivos (aunque no sólo de ellos) mediante la educación formal. Se trata de un medio para la adaptación a la sociedad y, más específicamente, de la preparación para el ingreso a las actividades laborales. O dicho de otro modo, en el capitalismo industrial los grupos sociales que podían acceder a la educación y el tipo de educación que recibían dependía del lugar que se esperara que cumplieran (si es que existía alguno) en los procesos fabriles.

La adquisición de técnicas, destrezas (skills) u otras habilidades por parte de las personas con discapacidad en el periodo del capitalismo industrial ha sido escasamente abordada por investigaciones históricas y se carece de fuentes estadísticas. Debido a esto, propondremos apenas algunas ideas tentativas.

Por lo pronto, esta ausencia de problematización surge debido a que durante el capitalismo industrial la educación de las personas con discapacidad no era un problema importante para los sectores dominantes toda vez que, como veremos más abajo (CSI organizacionales), no se esperaba que las personas con discapacidad se integraran a la maquinaria productiva capitalista. Aun en los casos en los que se buscaba que adquirieran destrezas, estas estaban marcadas por la axiología de la normalización. Así, por ejemplo, lo que las personas sordas denuncian como la "educación oralista" les prohibió o inhibió el desarrollo de la lengua de señas, y que en su lugar, promovió el aprendizaje de la lectura de labios, la lectoescritura y el habla (Cuevas, 2013: 703).

Esta tendencia es señalada por los trabajos que abordan la historia de la educación especial desde un enfoque crítico (Yarza de los Ríos, 2007; Martín Macías, 2010; Campos, 2015). Este tipo de educación nació en Europa occidental en el siglo XIX y comenzó a extenderse a los países latinoamericanos desde las primeras décadas del siglo XX. Surgió de la asociación entre medicina y pedagogía, situación que propició la puesta en marcha de un modelo de rehabilitación, donde el médico se ocupaba de la deficiencia y el maestro de la tarea de educar; en consonancia - se advierte así la articulación entre CSB y CSS - . La educación especial estaba signada, entonces, por un enfoque asistencial y de institucionalización segregada.

En ese marco, la rehabilitación consistía en el desarrollo de habilidades que se definían de acuerdo al tipo de deficiencia y puestos laborales específicos. Clases de música o de operación telefónica para las personas ciegas, talleres de fabricación de muebles para personas sordas, trabajo de oficina para personas en sillas de ruedas, etc. Esto debido a que las personas con discapacidad se veían imposibilitadas de ingresar al proceso de producción industrial que imponía una corporalidad sin "deficiencias" (Valencia, 2014: 14).

Cabe señalar que, al igual que otros grupos excluidos, no todas las personas con discapacidad tenían acceso a la educación especial y que al tratarse de una oferta educativa segregada y definida por el tipo de deficiencia, la misma no ofrecía los mismos saberes que recibía el resto de la población (masculina) en las instituciones estatales. Esto, a su vez, limitaba su acceso al nivel medio de la educación formal, que desde la primera mitad del siglo XX comenzaba a democratizarse en algunos países. De esta manera, los CSS que recibían las personas con discapacidad eran muy limitados, producto de la misma segregación y exclusión social.

En suma la educación especial fue la primera experiencia institucionalizada de transmisión masiva de saberes para las personas con discapacidad en muchos países, permitiendo el acceso a algunos aprendizajes o habilidades técnicas subjetivas. Sin embargo, presentaba restricciones en cuanto a los contenidos y exclusiones en el acceso a espacios físicos y simbólicos de los sistemas de educación formal ${ }^{5}$.

5. Una característica que, de hecho, se mantiene en buena medida en la actualidad. 
En el capitalismo informacional se profundiza la tendencia hacia la masificación de la educación formal, creciendo particularmente la educación superior formal. Mientras los valores (CSI axiológicos, que veremos más abajo) del período industrial implicaban compartimentaciones y exclusiones, los del capitalismo informacional buscan disolver barreras y están enmarcados por discursos relativos a la aceptación de la diversidad. Asimismo, las tecnologías digitales e internet contribuyen en la expansión de las formas de educación no formal (ej. cursos) e informal (autoeducación, aprendizajes no respaldados institucionalmente).

En este contexto, desde la década de 1970, el colectivo de las personas con discapacidad viene promoviendo un giro desde la educación especial a la educación inclusiva, en línea con las transformaciones en la totalidad capitalista, y particularmente en su axiología. Dicho giro propone transformar los sistemas educativos segregadores a otros que brinden los mismos aprendizajes (en igualdad de condiciones y con las mismas oportunidades), a los que accede la población general (Ainscow y Miles, 2008). Sobre todo en los países centrales y en algunos latinoamericanos, la propuesta, que tomó mayor relevancia desde la sanción de la Convención sobre los Derechos de las Personas con Discapacidad de Naciones Unidas, favoreció que algunos grupos de personas con discapacidad pudieran acceder, aun con limitaciones y obstáculos, a la educación universitaria (Abad et al., 2008; Fajardo, 2017) y, con ello, a nuevas destrezas y técnicas.

Asimismo, los cambios tecnológicos propios de este estadio del capitalismo han despertado el interés de algunos grupos económicos y académicos de brindar a estos colectivos espacios de formación y herramientas para desarrollar los CSS que emplean los trabajadores informacionales: el desarrollo de software, el teletrabajo (Villegas, 2013), el pensamiento computacional (López Escribano y Sánchez-Montoya, 2012), y otras actividades afines ofrecen vías relevantes para la formación e inserción laboral.

De cualquier forma, es importante notar que el modelo de educación especial sigue presente en muchos países y que las desigualdades en el acceso a la educación formal y las destrezas que ofrece no se han erradicado. Un informe de la Unesco (2018) con datos de 49 países muestra que las personas con discapacidad tienen menor probabilidad de asistir a la escuela, asisten menos años en promedio, es más improbable que completen la primaria o secundaria y que tengan habilidades de lectocomprensión básicas.

En cuanto a la adquisición de habilidades por fuera de la educación formal, las posibilidades de aprendizaje que ofrece Internet mediante videos tutoriales, audiolibros, cursos completos en variados formatos son masivas, aunque no contamos con medidas precisas sobre su impacto.

\section{Conocimientos de soporte intersubjetivo}

Los conocimientos de soporte intersubjetivo (CSI) reposan en los aspectos colectivos, intersubjetivos o, para usar el término usual, 'sociales' de la humanidad. Se apoyan en los vínculos entre los sujetos humanos que los preexisten y tienen una vida razonablemente autónoma de la de todo individuo particular. Hay al menos cinco tipos de conocimientos intersubjetivos: lingüísticos, organizacionales, reconocimiento, axiológicos y normativos (para un desarrollo mayor, ver Zukerfeld 2017, capítulo 3). 


\subsection{Lingüísticos}

Los CSI Lingüísticos se basan no sólo en la capacidad colectiva humana de codificar y decodificar conocimiento, sino sobre todo en la de crear códigos intersubjetivos (Saussure, 2011). Los significantes y significados, las palabras que se utilizan y las que quedan de lado, el sentido que se les atribuye, son medidas importantes del devenir de una sociedad 6 .

Así, uno de los indicadores relevantes respecto de los conocimientos lingüísticos es el de la variación en el uso determinados términos, expresiones o palabras. En el caso del campo semántico asociado a la discapacidad, cabe preguntarse por la variación de la participación de distintas expresiones y tratar de relacionar esos eventuales cambios con el pasaje del capitalismo industrial al informacional y, más genéricamente, preguntarse por la relación que presenta con otros flujos de conocimientos.

Para operacionalizar estos interrogantes, hemos recurrido a la base de Google Books desde 1800 a 2008 , a través de la herramienta Ngram Viewer. Específicamente, consultamos la participación porcentual (sobre el total de los libros editados en un año dado) de los términos: disability, impairment, hándicap (en la base de los libros en inglés) y discapacidad, deficiencia e invalidez (en la base de libros en español). Los resultados se visualizan en los gráficos 1 y 2 .

Gráfico 1. Evolución de la participación relativa de los términos disability, impairment y handicap en los libros editados en inglés (1800-2008)

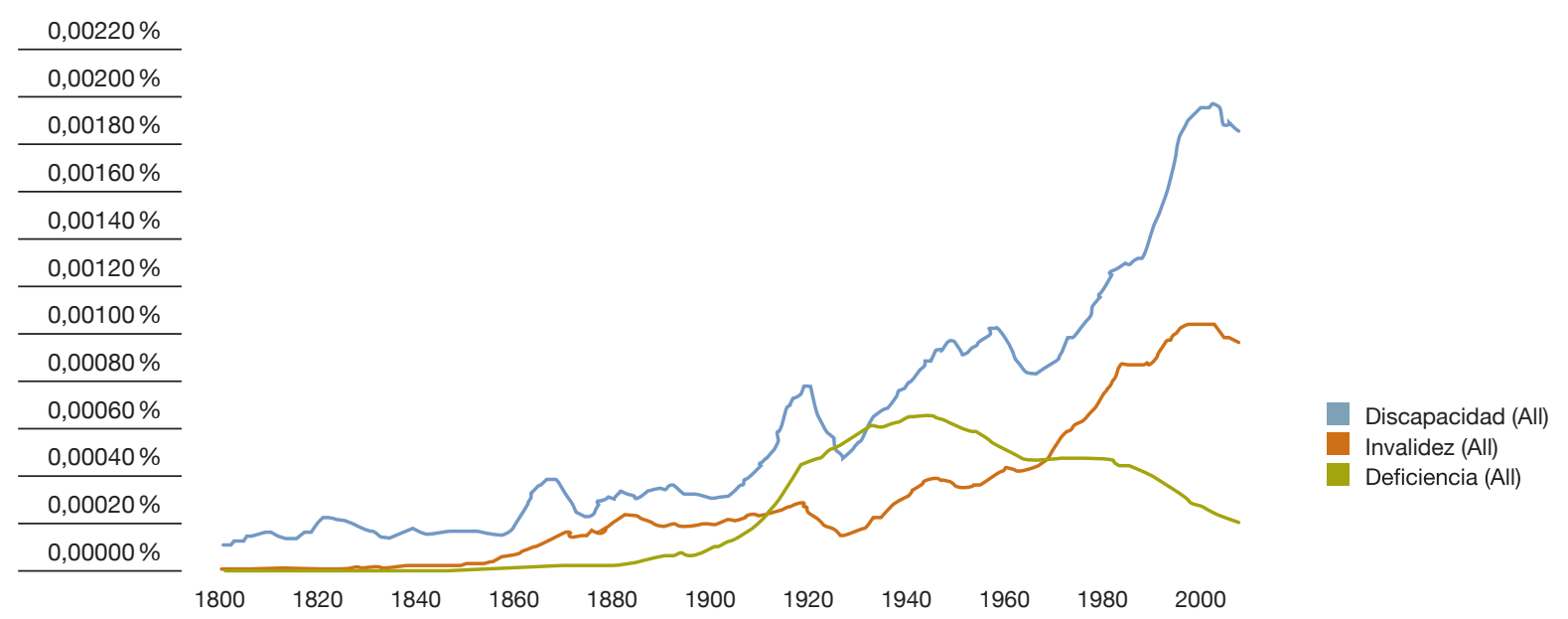

Fuente: elaboración propia en base a Ngram Viewer y Google Books.

6. Por motivos de espacio y para poder hacer lugar al análisis de los datos, no incluimos una caracterización de los rasgos lingüísticos generales del capitalismo industrial e informacional. El lector interesado puede encontrar un desarrollo de la cuestión en Zukerfeld, 2010 volumen 2.

7. Por supuesto, se trata apenas de un limitado indicador proxy, que en un análisis específico de los conocimientos lingüísticos habría que complementar con otros datos. 


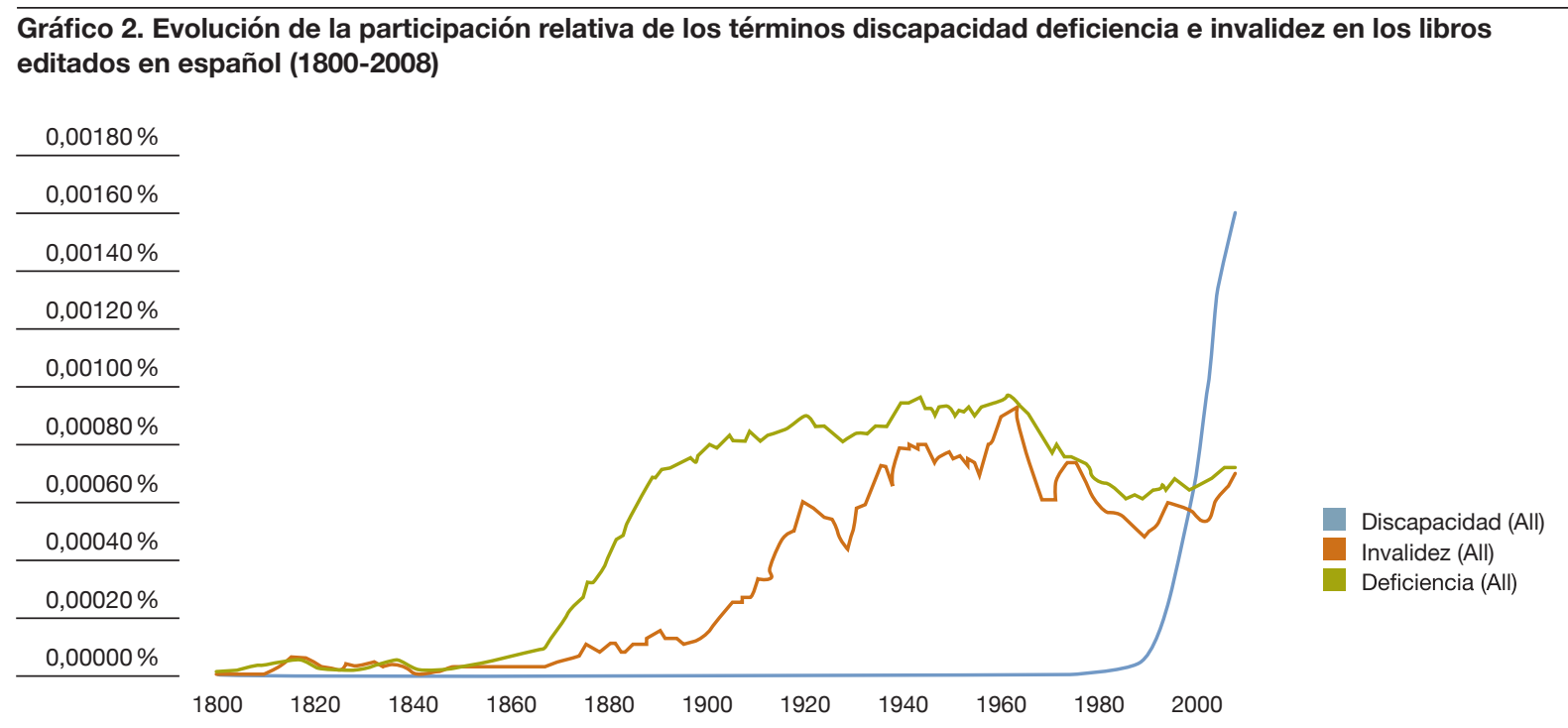

Fuente: elaboración propia en base a Ngram Viewer y Google Books.

Los datos de ambos cuadros sugieren (sin demostrar categóricamente) las siguientes reflexiones: el término discapacidad/disability ha incrementado su participación en el material publicado de manera considerable en ambos idiomas. Notablemente, en ambos idiomas registra en el último dato valores relativamente similares $(0,0016 \%$ y $0,0018 \%$ de los libros). Si bien en idioma inglés la tendencia al incremento es sostenida a lo largo del siglo XX, es interesante que desde fines de los 60 y comienzos de los 70 se produce un empinamiento mayor de la curva. En español, el cambio es más marcado, y a partir de los 90 se produce un ascenso notable del uso de la expresión. En ambos idiomas, el ascenso de la frecuencia del uso del término discapacidad/disability se verifica juntamente con el descenso relativo de otros términos, como deficiencia, invalidez y handicap.

Estos datos son compatibles con uno de los aspectos que señalaremos en los conocimientos de soporte intersubjetivo axiológicos: el ascenso en el capitalismo informacional del modelo social de la discapacidad en detrimento del modelo médico. Así, los términos que tenderían a asociarse más usualmente con las narrativas individualizantes y patologizantes están en descenso frente a aquellos que podrían incluirse en visiones en las que la discapacidad aparece como una construcción social.

En este sentido, es importante señalar el pasaje impulsado por organismos internacionales y colectivos de personas con discapacidad desde el término "discapacitado" a "persona con discapacidad". Aunque por motivos de espacio no incluimos más gráficos, podemos ver que los datos (nuevamente, del indicador proxy de usos en Google Books) son consistentes con la difusión de esta perspectiva. Desde fines de los 70 la expresión "person with disability" ha crecido visiblemente, aunque partiendo de valores muy bajos. En cambio, el uso relativo de la expresión "disabled person" (aunque partiendo de valores muy superiores), viene descendiendo desde los años 80 . Y la utilización de la expresión "disabled people" cae fuertemente desde fines de los 90. En español se observa que el uso de "persona con discapacidad" ha crecido claramente desde los 90, así como también lo ha hecho la expresión "persona discapacitada", pero en una medida 5 veces menor. 
También se producen otros cambios terminológicos en relación con la discapacidad: se reemplazan términos como "asistencia" e "integración", por "derechos" e "inclusión" - aunque, vale insistir - los cambios en los CSI lingüísticos no necesariamente operan cambios profundos en los CSI axiológicos, por lo que puede tratarse en muchos casos de cambios superficiales que no modifican las prácticas "excluyentes y discriminatorias" (Ferrante, 2015: 9)

\subsection{Reconocimiento}

EI CSI Reconocimiento hace referencia a las formas que asumen los vínculos por los cuales el sujeto se integra en grupos o colectivos humanos, es reconocido por otros sujetos y a través de los cuáles se reconoce a sí mismo. El reconocimiento refiere, así, a la triple operación de reconocer a otros, ser reconocido y autorreconocerse en una serie de lazos o vínculos.

Durante el capitalismo industrial el reconocimiento se ejerce mediado por la dicotomía individuo-sociedad (Williams, 1978; Bauman, 2000). Así, emerge y se impone la noción de individuo como ente autosuficiente, recortado del magma social, configurándose este modo de reconocimiento como la normalidad necesaria. El reconocimiento erigido alrededor de la noción de individuo autónomo, impulsado por el tipo ideal del empresario capitalista, se vincula sin mayor dificultad con el tratamiento dado a la discapacidad en el período: lo ajeno a la normalidad establecida se reconoce como anomalía y falla del sujeto individual

En cambio, en el capitalismo informacional el reconocimiento cobra un impulso fundamental mediante la conformación de redes vinculares, favorecidas y sostenidas por redes informáticas. La división entre individuo y sociedad se va transformando en la complementariedad entre individuos y redes, es decir, sujetos que se definen por su necesidad de conexión, y por el establecimiento de esas conexiones con la ayuda de otros. El reconocimiento está más en la conexión (aún la efímera y volátil) y menos en la autosuficiencia, a la vez que la diversidad de identidades desborda al individuo homogéneo del industrialismo (Castells, 1996; Sibilia, 2008; Deleuze, 1992).

Desde el lado de las personas con discapacidad, esto se expresa de varias maneras. Por un lado, el rechazo de la discapacidad como un fenómeno individual y las críticas hacia la sociedad y sus expertos constituyen una afirmación identitaria. Lejos de asumir el etiquetamiento industrial de seres que deben ser modificados o aislados, las personas con discapacidad reclaman el reconocimiento como sujetos cuyos derechos deben ser respetados: las redes que configuran la sociedad deben amoldarse a la identidad múltiple de las personas con discapacidad, y no viceversa.

Por ejemplo, encontramos esta forma de reconocimiento en grupos de sordos, que no se ven a sí mismos como deficientes o carentes de audición. Por el contrario, se identifican como una comunidad con una cultura propia, con particularidades que difieren del grupo mayoritario oyente, presentando características semejantes a las de otros pueblos minoritarios, como los pueblos indígenas. En este sentido, tienen una lengua visogestual que les es propia, la lengua de señas (CSI lingüísticos), y una serie de costumbres y vaIores (CSI axiológicos), como la manera de saludarse, de despedirse, de felicitar y de aplaudir, entre otras, que quieren difundir, en vez de eliminar (Paz y Salamanca Salucci, 2009: 32). Es por eso que estos flujos de reconocimiento chocan con tecnologías como el implante coclear (CSO Tecnologías y CSB posorgánicos), y 
más en general, con formas de negación de su identidad. De hecho, varias organizaciones de personas con discapacidad señalan que su existencia implica un enriquecimiento para la sociedad: "Nuestras vidas como personas con discapacidad proclaman el poder positivo de la diversidad. Nuestra experiencia enriquece a la sociedad” (Disabled Peoples' International Europe, 2000: 4-5, en López Mainieri, 2012: 47)

A su vez, en el capitalismo informacional emerge el reconocimiento positivo de la identidad de las personas con discapacidad mediante organizaciones colectivas específicas. En efecto, en el periodo actual del capitalismo surgen agrupaciones, federaciones y redes orientadas a la defensa del modelo social (ver CSI axiológicos) $^{8}$. En contraste, en el periodo industrial, predominaban las organizaciones de beneficencia y asistencia, identificadas con el modelo médico (ídem). Un hito importante en esta transición fue la Unión of Physically Impaired Against Segregation (Unión de Impedidos Físicos contra la Segregación, UPIAS por su sigla en inglés) nacida en el Reino Unido en 1972 y que, contrariamente a las organizaciones previas y contemporáneas enfocadas en la caridad, adopta un tono abiertamente político y teóricamente innovador que desembocaría en el modelo social de la discapacidad (ver más abajo).

En cuanto a América Latina, en el siguiente cuadro podemos encontrar algunos ejemplos de organizaciones nacionales, su país de origen y su año de fundación.

\begin{tabular}{l}
\hline \begin{tabular}{|l|c|c|}
\hline Tabla 1. Organizaciones de personas con discapacidad en América Latina, país y año de fundación \\
\hline Nombre de organización & País & Año \\
\hline Federación Colombiana de Organizaciones de personas con discapacidad Física -FECODIF- & Colombia & 2003 \\
\hline Red por los Derechos de las personas con discapacidad -REDI- & Argentina & 1998 \\
\hline Federaçao Brasileira das Associaçöes de Síndrome de Down -FBASD- & Brasil & 1994 \\
\hline Federación Nacional de Discapacitados -FENADI- & Chile & 1985 \\
\hline $\begin{array}{l}\text { Confederación Mexicana de Organizaciones en favor de las personas con discapacidad } \\
\text { Intelectual -CONFE- }\end{array}$ & México & 1978 \\
\hline Federación Nacional de Ciegos del Ecuador -FENCE- & Ecuador & 1985 \\
\hline
\end{tabular}
\end{tabular}

Fuente: elaboración propia.

Es posible advertir en el cuadro la existencia de un número importante de asociaciones y organizaciones desplegadas en la región. También existen organizaciones de alcance regional como la Red Iberoamericana de Organizaciones de personas con discapacidad y sus familias - RIADIS - o la Red de organizaciones de personas con discapacidad de Centroamérica y el Caribe - REDODICEC - l lo que da cuenta de un trabajo coordinado para interpelar a los Estados de la región. La organización reticular, como señalamos más arriba, se corresponde con una de las modalidades típicas del reconocimiento del capitalismo informacional. Por último, algunas de las organizaciones nacionales y regionales forman parte de la International Disability Alliance, Alianza Internacional de la Discapacidad, una organización con despliegue mundial fundada en el año 1999. La misma tuvo un papel relevante en las negociaciones políticas para la constitución, redacción

8. El modelo social tuvo su surgimiento, expansión y vigencia durante gran parte del periodo analizado, destacándose su cristalización jurídica en la sanción de la Convención. Sin embargo, esto no excluye la existencia y relevancia de otras organizaciones y colectivos que han desarrollado y desarrollan otras perspectivas sobre la discapacidad. 
y firma de la Convención sobre los Derechos de las personas con discapacidad en la ONU, y su posterior seguimiento, es decir, en la producción de CSI normativos y axiológicos.

Finalmente, cabe mencionar el aspecto del reconocimiento asociado a las palabras con las que se nombra a las personas con discapacidad, es decir, una faceta del reconocimiento asociada a cuestiones lingüísticas y axiológicas. Por ejemplo, el cambio desde "discapacitado" a "persona con discapacidad" implica el reconocimiento de que la discapacidad no es un atributo del individuo, sino del marco social que lo rodea, y es compatible asociar la identidad no a un infortunio médico individual, sino a una falta de derechos a nivel social.

\subsection{Organizacionales}

Los CSI Organizacionales aluden a la forma de conocimientos que se expresa en la división del trabajo en los procesos productivos y que es externa a cada sujeto que participa en ellos, constituyendo un saber colectivo que suele mantenerse aun cuando cambien los operarios de tal proceso productivo. Esto refiere tanto a los procesos productivos individuales, como a ramas de actividad y, más genéricamente, al metabolismo social, es decir, al lugar funcional que ocupan diversas clases de sujetos en el proceso de producción y reproducción de la sociedad.

En todos los niveles hay cambios profundos entre el capitalismo industrial y el informacional. Pero aquí nos quedamos con el nivel más agregado. La distribución de los roles y los cuerpos en el espacio y el tiempo, que durante el industrialismo estaba sujeta a la disciplina foucaultiana, se afloja en el capitalismo informacional (las sociedades de control en palabras del mismo Foucault (1993) y Deleuze (1992), en donde en líneas generales los cuerpos y los roles fluyen. Menos paredes, más redes; menos opacidad, más algoritmos. Sin embargo, aquí tenemos que señalar que esta discontinuidad está lejos de verificarse en el caso de las personas con discapacidad. Se advierte, más bien, una continuidad que tensiona las tendencias de otros flujos de conocimientos.

¿Cuál es el lugar que el proceso productivo capitalista les otorga a las personas con discapacidad? Es decir, ¿en qué lugar funcional ubica la maquinaria productiva a las personas con discapacidad? Eduardo Joly ofrece una respuesta simple basada en una perspectiva marxista y foucaultiana: la noción de discapacidad se configura junto con el capitalismo. Emerge asociada a la normalidad para etiquetar a los sujetos que no resultan útiles para los procesos productivos del capitalismo y que engrosan el segmento consolidado del ejército industrial de reserva (Joly, 2007; Oliver, 1990). Así, los conocimientos intersubjetivos organizacionales, es decir, la organización capitalista del aparato social, es la que definiría la "normalidad" y entre sus múltiples alteridades, la discapacidad. Analizar a la organización como conocimiento intersubjetivo nos permite dar cuenta ya no sólo de la vocación de capitalistas individuales o de estados nacionales, sino de una creencia arraigada colectivamente entre capitalistas y trabajadores, personas con y sin discapacidad.

Consecuentemente, la distribución organizacional de los cuerpos ubica a las personas con discapacidad en dos ámbitos: el no empleo y la pobreza. El no empleo refiere a la exclusión del mundo del trabajo, que puede tomar la forma de desempleo abierto (personas que buscan activamente trabajo y no lo encuentran), subempleo (personas que trabajan menos horas de las que quisieran) y, más importante, la salida de la 
población económicamente activa (personas que no buscan empleo, frecuentemente por desánimo). Un citado informe de la Organización Internacional del Trabajo (OIT, 2003) señalaba que en "muchos países en desarrollo" la tasa de desempleo de las personas con discapacidad es del "80\%". En las estadísticas recientes de la misma OIT y tomando la noción de desempleo en el sentido estricto y acotado, se observan datos que van en la misma dirección, pero con diferencias mucho menos extremas. En las bases ILOSTAT puede encontrarse que efectivamente la participación en el desempleo de las personas con discapacidad es algunos puntos (entre 2 y 5) mayor que la de las personas sin discapacidad, y que las mujeres tienen una situación peor aún que la de los varones. Sin embargo, cuando se mide la tasa de empleo en los EEUU (relevante por contar con una amplia base estadística y por su rol en el surgimiento del capitalismo informacional) se observa que la situación de las personas con discapacidad es notablemente más grave y que la tendencia, lejos de revertirse, ha empeorado en los últimos años. Así, mientras la tasa de empleo de las personas sin discapacidad ronda el $70 \%$, la de las personas con discapacidad nunca superó el $30 \%$ y en 2014 (último dato disponible) no llegaba al 15\%.

Gráfico 3. Tasa de empleo y pobreza de personas con y sin discapacidad (EEUU, 1981-2014)

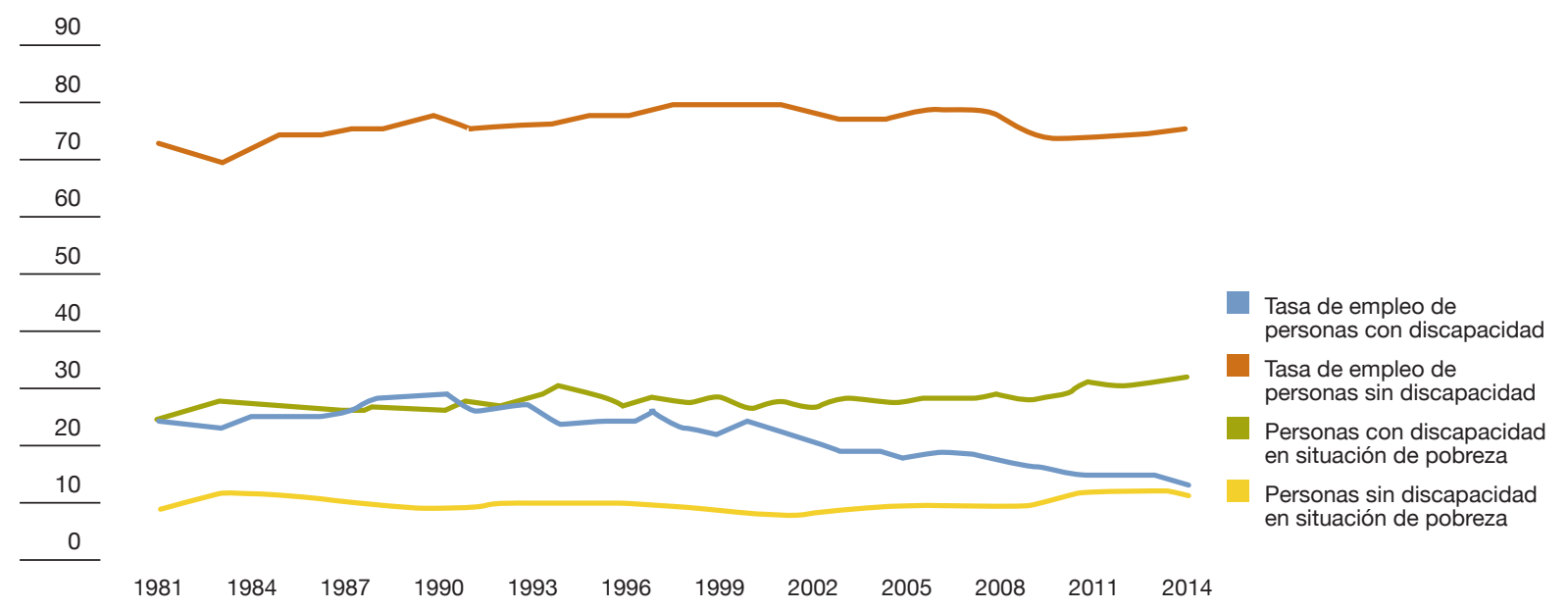

Fuente: elaboración propia en base a Von Schrader y Lee, 2017.

En cuanto a la relación entre discapacidad y pobreza, vemos que se produce un efecto espiralado: la discapacidad (por la falta de empleo digno y bien pagado; por los gastos adicionales que supone) incrementa las posibilidades de empobrecimiento, y la pobreza genera aumento de las probabilidades de discapacidad: malnutrición, programas de salud insuficientes, accidentes en hogares precarios y sobrepoblados, etc. (Coleridge, 1993: 64) En el gráfico 3 podemos ver esto con claridad: la pobreza entre las personas con discapacidad no sólo no ha disminuido, sino que se ha incrementado en los últimos años.

Este dato está relacionado con la desigualdad en los ingresos percibidos por los hogares. Es decir, entre los pobres y los no pobres, los ingresos de los hogares con personas con discapacidad son sustancialmente menores que los que no son habitados por personas con discapacidad. Más aún, la distancia entre ambos ha ido aumentando en los últimos años, como lo muestra el gráfico 4. 


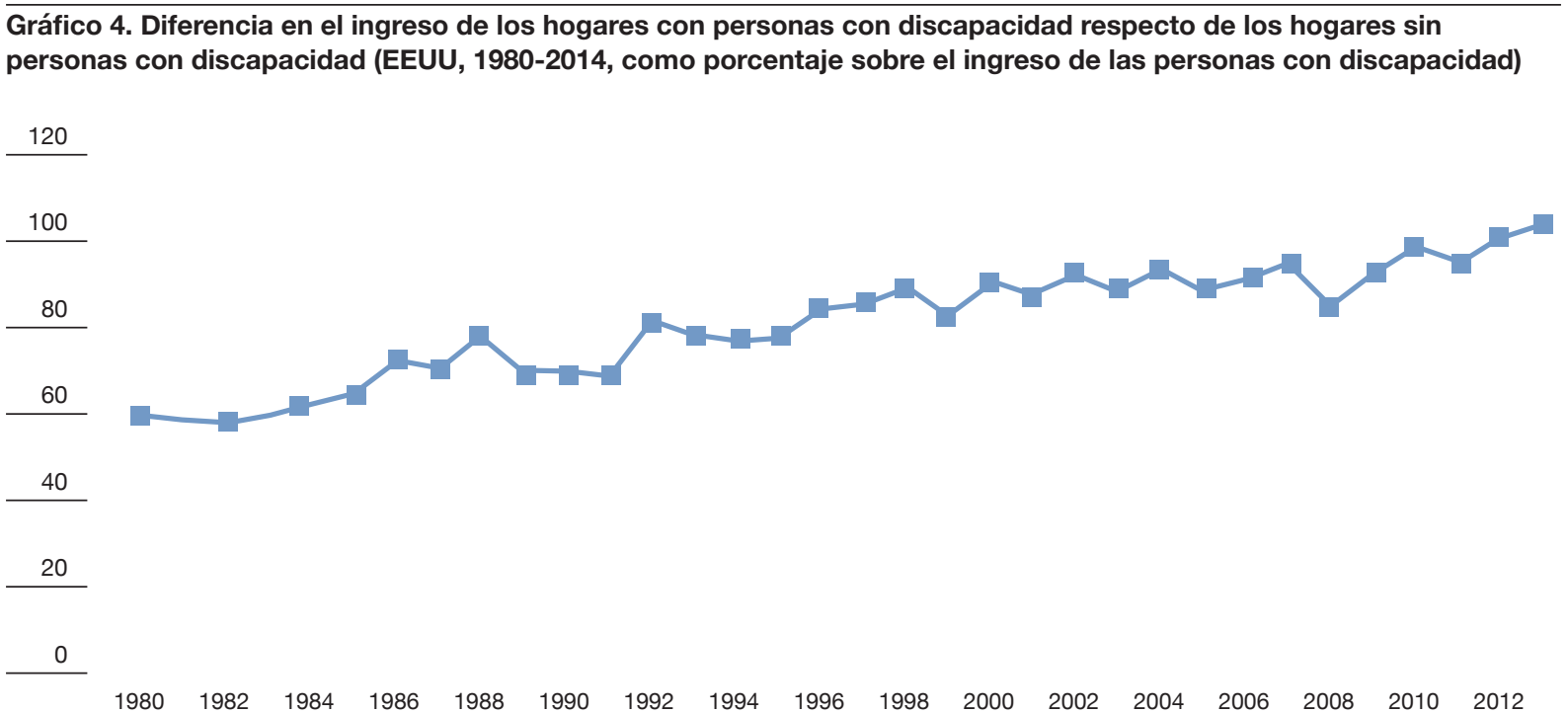

Fuente: elaboración propia en base a Von Schrader y Lee, 2017.

Así, si en 1980 el ingreso de los hogares con personas con discapacidad era un $60 \%$ menor que los de los hogares sin personas con discapacidad, en 2013 esa diferencia era de un $100 \%$.

En suma, el capitalismo tiende a ubicar a la discapacidad en la intersubjetividad organizacional, en su metabolismo colectivo, en el desempleo, la pobreza y actúa reduciendo los ingresos de los hogares que cuentan con personas con discapacidad. En principio, el capitalismo informacional no sólo no ha modificado esta tendencia, sino que parece haberla profundizado.

\subsection{Axiológicos}

Los CSI Axiológicos designan, simplificadamente, a todas las formas de creencia intersubjetiva que configuran las anteojeras a través de las cuales nos representamos el mundo. Conceptos como formas de vida (Wittgenstein, 1953), imaginario social (Castoriadis, 1997) e ideología (Zizek, 1989), entre otros, aluden a este plano, subrayando que la intersubjetividad se traduce hacia la subjetividad implícita, es decir, no necesariamente conciente. Esto incluye pero excede a la distinción entre lo correcto y lo incorrecto, entre el bien y el mal.

La axiología del capitalismo industrial está fuertemente signada por la idea de normalidad y disciplina. Las mercancías en las fábricas y los sujetos en las familias, escuelas y hospitales debían estandarizarse, amoldarse a ritmos regulares y previsibles de la mano de la ciencia allí donde sea posible. La variabilidad y la anomalía, en cambio, habrían de ser corregidas en los productos y humanos.

En este marco, la axiología de la discapacidad en el capitalismo industrial está marcada por el ya mencionado modelo médico. Este concibe a la discapacidad como producto de una enfermedad o cualquier alte- 
ración de la salud, que una vez diagnosticada, requiere asistencia médica y luego rehabilitación (Palacios, 2008: 66). Esta perspectiva es solidaria del concepto de normalidad y de individualidad y está asociada a las sociedades disciplinarias, en el sentido de Foucault. El trato dado a la anomalía podía tomar diversas formas: la corrección, el ocultamiento, el confinamiento y, en algunos casos, la eliminación física de los individuos. Como en todos los casos, los flujos de conocimientos son eficientes cuando se traducen de unos soportes a otros. Así, esta axiología emergió junto con variadas tecnologías (desde instituciones de encierro a bastones), normas (por acción u omisión), lenguajes (“minusválido", "discapacitado"), destrezas subjetivas (como técnicas médicas), etc.

Una variedad del modelo médico es la de la llamada eugenesia. Implica, de un lado, la intervención concreta sobre los CSB (señalada en el apartado específico); de otro, una axiología definida por 3 rasgos: "a) la idea de que es posible perfeccionar al ser humano, b) la existencia de subhumanos, es decir seres que no son considerados como personas y c) la idea de perfección biológica y psicológica ligada al progreso en distintos sentidos sociales" (Villela y Linares, 2011: 189). Lo que la distingue como una axiología característica del capitalismo industrial es su asociación con el conocimiento científico del período (la teoría de la evolución de Darwin y los conocimientos biológicos del cuerpo humano), y la intervención de los Estados por medio de su poder político sobre su población. Son estos dos elementos los que nos permiten definir a la eugenesia como el ejercicio de una estrategia biopolítica (Ballejo y Miranda, 2004: 426; Foucault, 2010).

En el capitalismo informacional, la axiología privilegia crecientemente las nociones de multiplicidad y diversidad, que dejan de ser rechazadas - al menos discursivamente-, y pasan a ser parte del repertorio oficial de valores esperables. La otredad relegada en el capitalismo industrial, ahora es festejada en los discursos de la posmodernidad, la política de la identidad y la corrección política en general. Del esencialismo se pasa, tendencialmente, al relativismo y constructivismo social. A su vez, se impone la necesidad de conexión, esto es, se valora la cantidad de conexiones, principalmente reticulares a través de internet, que establecen los sujetos. Estar conectado es un imperativo moral.

En cuanto a la discapacidad, el cambio axiológico más notable es el desarrollo del modelo social de la discapacidad. Este surge en el mundo anglosajón en los años 70. En él confluyen producciones académicas y militantes, individuos y organizaciones de personas con discapacidad.

En este modelo la discapacidad refiere a la incapacidad de la sociedad para dar una participación completa a las personas con deficiencias (impairments ${ }^{9}$ ) en la vida social.

Así, el modelo social distingue entre discapacidad (disability) y deficiencia (impairment). Mientras la deficiencia hace referencia a un atributo o falta de atributo individual, la expresión discapacidad se reserva para las restricciones causadas por la falta de adecuación y atención de la sociedad a las necesidades de los individuos con deficiencias (Ferrante, 2015). Esta distinción surge de la mencionada UPIAS. En su perspectiva, mientras deficiencia refiere a una descripción, discapacidad señala no sólo una injusticia, sino una forma de opresión.

Desde nuestra perspectiva, el modelo social puede comprenderse mejor mediante su relación con los distintos tipos de conocimientos: la deficiencia (impairment) refiere a conocimientos de soporte biológico, 
mientras que la discapacidad se vincula con conocimientos de soporte subjetivo, intersubjetivo y objetivo que niegan una inclusión plena a las personas con discapacidad. Así, desde el materialismo cognitivo, el modelo social podría expresarse aproximadamente como una axiología que aspira a que la sociedad produzca transformaciones en los conocimientos subjetivos (dando por ejemplo acceso a la educación formal, no formal e informal), intersubjetivos (respetando los lenguajes de señas, por ejemplo, modificando el lenguaje que era propio del modelo médico, generando organizacionalmente inclusión, estimulando el reconocimiento de la identidad y de los derechos, sancionando y cumpliendo normativas inclusivas para las personas con discapacidad) y objetivos (mediante toda clase de tecnologías que favorezcan la inclusión y acceso a flujos de información).

El modelo social, efectivamente, se traduce desde la axiología hacia otros soportes, como normas (por ejemplo, la Convención sobre los Derechos de las Personas con Discapacidad, como veremos más abajo) pero también hacia tecnologías. Respecto de éstas hay dos valores importantes: el principio de accesibilidad y los criterios de diseño universal.

Desde un punto de vista más general, es importante notar que en el modelo social de la discapacidad se expresan rasgos axiológicos que, siendo contrarios a los preceptos del capitalismo industrial, se han vuelto extendidos en el capitalismo informacional: la diversidad y la conexión (la idea de que los sujetos humanos, para satisfacer sus necesidades y, a la vez, para ser útiles en los procesos capitalistas deben poder conectarse física y digitalmente).

Con todo, el modelo social se encuentra complementado o tensionado por otras axiologías que disputan el sentido de la discapacidad de manera tácita o explícita en el capitalismo informacional.

Por un lado, cierta continuación más o menos sutil del modelo médico y aún de la eugenesia. Tomando como ejemplo los diagnósticos genéticos prenatales (CSB) Romañach y Arnau (2006, en López Mainieri, 2012: 45) plantean que: "Ios medios han ido cambiando con el tiempo, pero el fin es el mismo, no dejar nacer a personas que son diferentes, porque las percibimos como 'inferiores'. O dicho de otro modo, que sus vidas no son dignas de ser vividas".

Ante estos planteamientos, el movimiento de las personas con discapacidad en Europa no sólo se ampara en el modelo social, es decir, en el valor de la construcción social de la discapacidad, sino que reivindica un valor muy importante para el capitalismo informacional: el de la diversidad. Por ejemplo:

...la genética humana representa para nosotros una amenaza, porque mientras promete la curación o la contención de posibles deficiencias, lo que en realidad ofrece actualmente son unas pruebas genéticas destinadas a detectar características percibidas como indeseables (...) Mantener la diversidad es tan imprescindible para la humanidad como lo es para la vida en su totalidad. (Disabled Peoples' International Europe, 2000: 4-5, en López Mainieri, 2012: 47).

Finalmente, la otra narrativa axiológica que sin ser originaria del capitalismo informacional subsiste en él es la de la tragedia médica personal y más precisamente, su relación con la pena (Ferrante, 2015: 37). Lo novedoso es su persistencia, actualización y disputa simbólica en el presente contexto en el que la axiología del modelo social y la diversidad ya tienen una difusión considerable. 
En suma, parece haber en el capitalismo informacional al menos cuatro ejes axiológicos circulando alrededor de la discapacidad. Dos de ellos son nuevos y propios de esta etapa: la construcción social de la discapacidad y la valoración de la diversidad. Los dos restantes continúan, de modos más o menos directos, valores que vienen de antaño: el valor de la normalización y la biologización, y el de la tragedia médica personal y la pena.

\subsection{Normativos}

Los CSI Normativos o Regulatorios refieren a la internalización intersubjetiva de ciertas pautas de conducta que están respaldadas por sanciones de diversa índole. Hacen referencia a las distintas clases de normas (leyes, decretos, actas, ordenanzas, tratados, etc.), a los fallos judiciales y a las instituciones, en la medida en que están encarnados en el entramado colectivo.

Los CSI normativos del capitalismo industrial tienen una faceta indudablemente asociada a la constitución de una sociedad disciplinaria, mediante la regulación legal del tiempo y el espacio, y del tránsito de los cuerpos por ellos.

Esto se puede ejemplificar con respecto a la discapacidad mediante tres tipos de normas. En primer lugar, las regulaciones orientadas a segregar a las personas con discapacidad en instituciones de encierro (manicomios, hospitales, cárceles) para separarlas del resto de la población, y en algunos casos para rehabilitarlas. Se trataba de normas que prohibían el tránsito o permanencia de las personas con discapacidad en los espacios públicos o que prohibían la "mendicidad" y la "holgazanería", caracterizando a las personas con discapacidad como enfermas o incapaces para las actividades productivas (Cayuela, 2017). En segundo lugar, un conjunto de normas eugenésicas que se basaban en limitar los derechos reproductivos individuales de las personas con discapacidad, por medio de la prohibición del casamiento o la esterilización forzosa. Y bajo el pretexto de conservar la salud genética de las generaciones futuras, referidas más arriba como políticas de eugenesia negativa. Por último, legislaciones que buscaban garantizar la seguridad social a los obreros que habían adquirido una "deficiencia" como consecuencia de sus actividades laborales. Así, establecían pensiones para los obreros que habían sufrido accidentes o contraído alguna enfermedad en las fábricas, o que por su edad avanzada ya no podían trabajar. Esto se materializó en las leyes de Accidentes de Trabajo y de Enfermedades, Jubilación y defunción (Saborido, 2002, en Valencia, 2014: 15).

En cuanto al capitalismo informacional, las regulaciones en muchos casos buscan cristalizar la axiología del período. Así, la diversidad y la conexión se expresan en la eliminación, o al menos limitación, de las segregaciones y exclusiones rígidas del período anterior. Se trata de normas de afirmación de la diferencia, de reconocimiento de múltiples identidades.

La regulación de la discapacidad tuvo un hito sobre el fin del industrialismo, en la Declaración de los Derechos Humanos del Hombre de 1948 y uno más importante y específico sobre el inicio de la etapa informacional: la Declaración de los Derechos de los Impedidos de la Organización de las Naciones Unidas (ONU) en 1975 que, aunque sin dejar de lado por completo el enfoque de la rehabilitación y la asistencia, incorporaba los derechos civiles. Esta última expresa regulatoriamente demandas de organizaciones del movimiento de vida independiente en la década de los sesenta en los Estados Unidos y luego en Europa (Palacios y Romañach, 2006). Vemos así la complementariedad entre los CSI Reconocimiento y los CSI Normativos. 
En este contexto de ampliación de derechos, y a lo largo de las últimas tres décadas del siglo XX, algunos países europeos y latinoamericanos establecerían normativas para garantizar el empleo y la no discriminación de las personas con discapacidad. Asimismo, en América Latina se advierte como un hito relevante la firma de la Convención Interamericana para la eliminación de todas las formas de discriminación contra las personas con discapacidad de la Organización de los Estados Americanos en 1999. Esta incorporaría la accesibilidad al medio físico y la obligación de los Estados partes a trabajar en la concientización sobre la igualdad de los derechos de las personas con discapacidad (OEA, 1999).

Ahora bien, el cambio al paradigma de los Derechos Humanos se establecería en el plano normativo a nivel mundial con la Convención sobre los Derechos de las personas con discapacidad de la ONU en el año 2006. Este es el instrumento jurídico que supera la visión de las personas con discapacidad como sujetos de rehabilitación o asistencia para considerarlas como sujetos de derechos plenos. De esta manera, la Convención plantea como principios la autodeterminación, la vida independiente, la accesibilidad, el diseño universal, la igualdad de oportunidades, la vida digna, entre otros. Esto a su vez amplía los derechos de las personas con discapacidad a tener acceso a la educación, a la salud, al trabajo, a la justicia, a la vivienda, a una familia, a la tecnología, por mencionar algunos (Naciones Unidas, 2006).

No obstante, estos derechos se cumplen de manera desigual alrededor del mundo y en diversas zonas se cumplen sólo raramente (OMS, 2011; CDPD, 2019). En efecto, la sanción de normas no indica su intersubjetivación, su cumplimiento efectivo. Aunque enumerar los incumplimientos sería extenso, la literatura académica señala algunas cuestiones a las que ya se ha aludido, como las barreras en el sistema educativo, una marcada desigualdad económica y bajos niveles de empleo, y el no reconocimiento de las personas con discapacidad como sujetos de derecho (Ferrante, 2014). Pero también el limitado acceso a tecnologías digitales desarrolladas bajo los principios de accesibilidad y el diseño universal (Ferreira y Díaz Velázquez, 2009; Soto, 2017), a las que nos referiremos en la próxima sección.

\section{Conocimientos de soporte objetivo}

Los conocimientos de soporte objetivo (CSO) son aquellos que se hallan cristalizados por fuera de los seres vivos, materializados en los más variados bienes. Se dividen en dos clases. De un lado, tenemos a aquellos conocimientos que se concretizan en la forma que asume un bien determinado con un propósito instrumental: los llamamos tecnologías. Dentro de las tecnologías, a su vez, distinguimos entre las tecnologías que manipulan, procesan, trasladan, acumulan o convierten materia/energía y las que lo hacen con la información. Por otro lado, distinguimos en base a su fuente energética: les llamamos herramientas a las que tiene una fuente energética biológica, y máquinas a las que tienen fuentes energéticas que no dependen de seres vivos. Un subgrupo particular de tecnologías de la información que son máquinas es el de las tecnologías digitales (Zukerfeld, 2014).

El otro tipo de conocimiento de soporte objetivo es el codificado. Le llamamos información a los conocimientos codificados que se materializan en el contenido simbólico del soporte objetivo. Un tipo particular 
de información es la información digital. Entre otras propiedades, la información digital es replicable, esto es, se puede clonar con costos marginales cercanos a 0.

El capitalismo industrial está marcado, ante todo, por las tecnologías de la materia/energía que son máquinas: desde la máquina de vapor y hasta el automóvil; pero también por las tecnologías de la información analógicas, como el telégrafo o el disco. El capitalismo informacional, en cambio, se distingue por la masificación de las tecnologías digitales (computadoras o teléfonos móviles) y la información digital, alrededor de Internet.

Para caracterizar la relación entre la discapacidad y los distintos tipos de tecnologías e información, comenzamos reflexionando sobre las tecnologías de la materia/energía en los períodos industrial e informacional, y continuamos con las de la información en uno y otro período.

Un campo fértil en el que podremos observar las transformaciones de las tecnologías de la materia y la energía de uno a otro periodo del capitalismo es el de la vinculación de éstas con la discapacidad motriz. En el capitalismo industrial esta relación se manifestó en el desarrollo de herramientas simples y complejas orientadas al desplazamiento en el entorno físico y al movimiento corporal de las personas con discapacidad: sillas de ruedas, bastones, prótesis, etc. También algunas de esas herramientas complejas devinieron en máquinas, como las sillas de ruedas eléctricas que, inventadas en la década de 1930, comienzan a difundirse luego de la Segunda Guerra Mundial. La tecnología, como señalan diversos autores (Feenberg, 1991; Winner, 1987) porta valores (CSI axiológicos) objetivados en ella. En este sentido es que estas tecnologías fueron concebidas en el campo de la Ingeniería de la Rehabilitación (Martínez Mateus y Rios Rincón, 2006) que adopta desde sus orígenes el enfoque del modelo médico o rehabilitador (ver en los CSI axiológicos). Es por ello que todos los desarrollos tecnológicos de este campo buscan recuperar las "funcionalidades corporales" perdidas por la "deficiencia" en el sujeto con discapacidad, sin intervenir en el entorno social.

En el capitalismo informacional se pueden observar dos tipos de transformaciones en relación a las tecnologías de la materia y la energía. Por un lado, la difusión de las máquinas que existían previamente y la penetración de las tecnologías digitales en ellas. En el caso de las sillas de ruedas, se aprecia la expansión - siempre relativamente acotada - de las eléctricas, que permiten incrementar la autonomía para las personas con discapacidad. A su vez, siguiendo un movimiento clásico de otras tecnologías de la materia y la energía, podemos ver como los controladores electrónicos, típicamente joysticks, pero también otros, modifican la experiencia de uso. Los sensores y actuadores digitales permiten gobernar las tecnologías de la materia y la energía de un modo mucho más simple y poderoso que en el período previo. El componente cognitivo, ahora informacionalizado, empodera a los usuarios.

Por otro lado, menos obvio y más profundo, frente al dominio excluyente de las tecnologías centradas en el sujeto individual en la etapa previa, ganan ahora protagonismo las tecnologías centradas en el entorno. En este sentido, mientras una silla de ruedas parte de los requerimientos de un usuario individual, una rampa se construye pensando en el entorno donde será instalada. Así, en el capitalismo informacional comienzan a desarrollarse herramientas y máquinas que contribuyen a la autonomía y la accesibilidad en espacios urbanos, edificios, transporte, etc.

Por supuesto, estas transformaciones se asocian escasamente con innovaciones puramente tecnológicas, y se deben más bien en transformaciones en la dinámica axiológica del capitalismo. 
En cuanto a las tecnologías de la información, focalizamos la atención en el caso de la discapacidad visual. Fue en Francia durante los inicios del capitalismo industrial donde se desarrolló la primera tecnología de la información que permitió el acceso de las personas con discapacidad visual de forma masiva a la escritura y la lectura: el sistema Braille. Creado por el joven ciego Louis Braille a inicios del siglo XIX, "está diseñado para poder ser explorado de forma táctil y su unidad básica está constituida por la celdilla. Dentro de cada celdilla se pueden situar un conjunto de puntos en relieve en seis posiciones diferentes. Las distintas combinaciones de puntos dan lugar a diferentes caracteres, pudiéndose así representar todas las letras del alfabeto, los números y también los diferentes signos de puntuación” (Simón et al., 1995: 91).

Por sus características, el braille incluye una tecnología de la información de tipo analógica: un papel con puntos en relieve, elaborados con un punzón que sigue los casilleros en una regleta de metal o madera. Desde esta descripción, los aportes a nivel material del capitalismo industrial para esta tecnología fueron: la mayor disponibilidad de papel, insumo que hasta entonces era un bien escaso y de alto costo; un incremento en la producción de madera y metal como así también en el número de herramientas para la fabricación de piezas de estos materiales, lo que contribuyó a la fabricación masiva de los punzones y las regletas ${ }^{10}$.

En el capitalismo informacional, las tecnologías digitales posibilitan mecanismos de traducción semiótica entre signos visuales, sonoros y táctiles, como así también la automatización en los procesos de traducción de información digital a analógica.

En este escenario, el braille ha vivido transformaciones tecnológicas a partir de dos máquinas que emplean información digital y que pueden expresar este sistema de signos táctiles: la línea braille y la impresora (Ferrante, 2013: 32).

Otro modo en el que se manifiesta este potencial de traducción es a través de aplicaciones de sistemas TTS (Text To Speech, por su sigla en inglés) y lectores de pantalla ${ }^{11}$. Los primeros realizan una síntesis de voz humana generada desde textos digitales que, entre otras aplicaciones, permite producir audio libros. Los segundos, en tanto, permiten acceder a los textos digitales por medio de signos sonoros empleando tarjetas de sonido (Labrada, 2011: 56). De este modo, realizan una descripción inteligente y sintética de los elementos visuales de la pantalla para luego expresarla por sistemas TTS o líneas braille. Esto le permite al usuario con discapacidad visual navegar, reconocer, interactuar y utilizar la interfaz de los programas, siempre que los sistemas operativos los soporten (Windows, Linux, IOS, Android) y los contenidos sean accesibles.

Así, a partir de traducir entre sí los signos visuales, sonoros y táctiles, estas tecnologías digitales han favorecido el acceso a la comunicación en el espacio de los textos hipermediales para las personas con discapacidad visual.

Sin embargo, pese a la expansión de las tecnologías digitales propia de la presente etapa, hay que señalar que las personas con discapacidad se enfrentan a una brecha digital de la discapacidad (Vicente y López, 2010; Dobransky y Hargittai, 2016) o una tercera brecha digital (Ragnedda, 2017; van Dijk, 2018). Por ejem-

10. El braille aparece analizado aquí respecto de su aspecto tecnológico, pero el sistema también incluye CSS implícitos (la técnica humana de la lectura del sistema) y CSI Lingüísticos (un código de equivalencias).

11. Cabe señalar que esto ya se hacía desde la invención de las primeras grabadoras de cintas a casete (Portales, 2004). La novedad reside en el aumento de velocidad de la producción de la pieza sonora. 
plo, según datos del Pew Research Project, en los EEUU las personas con discapacidad tienen un acceso de unos 20 puntos porcentuales menor que las personas sin discapacidad a las tecnologías asociadas con el capitalismo informacional e Internet (smartphones, computadoras, tablets, acceso a banda ancha), como lo muestra la tabla 2.

Tabla 2. Acceso a distintas tecnologías digitales por parte de personas con y sin discapacidad (EEUU, 2017)

\begin{tabular}{|l|c|c|}
\hline Tecnología & Personas con discapacidad & Personas sin discapacidad \\
\hline Computadora de escritorio o portatil & $61 \%$ & $81 \%$ \\
\hline Smartphone & $58 \%$ & $80 \%$ \\
\hline Tablet & $36 \%$ & $54 \%$ \\
\hline Conexión por banda ancha & $57 \%$ & $76 \%$ \\
\hline
\end{tabular}

Fuente: Anderson and Perrin, 2017.

Del mismo modo, respecto del consumo de información digital, un indicador proxy relevante es el de la frecuencia con la que se conectan a Internet, que presentamos en la tabla 3.

Tabla 3. Frecuencia en el uso de Internet en personas con y sin discapacidad (EEUU, 2017)

\begin{tabular}{|l|c|c|}
\hline Uso de Internet & Personas con discapacidad & Personas sin discapacidad \\
\hline No se conectan a Internet nunca & $23 \%$ & $8 \%$ \\
\hline Usan Internet todos los días & $50 \%$ & $79 \%$ \\
\hline
\end{tabular}

Fuente: Anderson and Perrin, 2017.

Las personas con discapacidad que se conectan todos los días a Internet son un $29 \%$ menos que las que no tienen discapacidad. Del mismo modo, las personas con discapacidad que no se conectan nunca a Internet son un $15 \%$ más que las personas sin discapacidad.

De cualquier forma, junto con este dato sobre la brecha hay que retener que un $50 \%$ de las personas con discapacidad (en los EEUU) utiliza Internet todos los días y que un $77 \%$ se conecta alguna vez, lo cual habla de un importante uso potencial de la información digital.

La literatura académica ha discutido la relación entre internet, discapacidad y sociedad reiteradamente (Goggin y Newell, 2003; Ellcessor, 2016; Ellcessor, et al., 2017; Ellis y Kent, 2011). Emergen algunos tópicos claros que son, en mayor o menor medida, usuales también en otros sectores sociales. Primeramente, las posibilidades para expandir las prácticas de comunicación, juego, disfrute, expresión y acceso a la cultura (Raja, 2016). En segundo lugar, la exposición a ataques, agresiones y discriminación (Bustos et al., 2019). En tercer lugar, la explotación del trabajo impago (incluyendo la producción de datos, contenidos y el consumo de publicidad). Finalmente, un aspecto específico: las limitaciones de accesibilidad y el reclamo para que las distintas plataformas hagan todos los esfuerzos necesarios para garantizar la accesibilidad (Yu et al., 2019). 


\section{A modo de cierre}

Abordar la discapacidad desde el materialismo cognitivo nos ha permitido, esperamos, realizar algunas contribuciones parciales:

1. Integrar los distintos niveles de lo que aquí llamamos conocimientos (biológicos, subjetivos, intersubjetivos y objetivos) en un mismo análisis. Esto busca una aufhebung (negación, recuperación y superación) de las perspectivas que enfatizan solo una dimensión (en general la biológica, pero también la social, subjetiva o tecnológica), recuperando la categoría de totalidad.

2. Sugerir las contradicciones entre distintos flujos de conocimientos. Por ejemplo, las normas apuntan en una dirección, pero las tecnologías lo hacen en otra. $\mathrm{O}$ aun dentro de un mismo tipo de conocimientos, como en el caso de los axiológicos, encontramos contradicciones. La riqueza de analizar una totalidad dialéctica consiste, precisamente, en el diálogo de la diversidad con sus tensiones constitutivas. No se trata de una convivencia armoniosa, sino de un devenir dinámico, de una totalidad múltiple y plural.

3. Enmarcar las transformaciones respecto de la discapacidad en el cambio que supuso el pasaje desde el capitalismo industrial al informacional. Así, más allá de que el capitalismo tenga algunos aspectos constantes que lo definen en cualquiera de sus etapas, y que esas constantes tengan relación con la discapacidad, o discapacidades, también resulta fundamental ver cómo las variaciones del devenir capitalista se relacionan con transformaciones respecto de la forma en que se ontologiza la discapacidad.

Por supuesto, este artículo es un aporte inicial y está colmado de limitaciones y deudas. Entre otras, podemos enumerar las siguientes:

Ninguno de los conocimientos se analizó de manera exhaustiva - porque se privilegió la perspectiva sistémica de la totalidad por sobre los detalles-. En futuras indagaciones deberemos pasar de este universal abstracto (en términos hegelianos) a los particulares concretos, y estudiar en detalle cada tipo de conocimiento.

Asimismo, en virtud de los datos disponibles, no pudimos detenernos en las especificidades de América Latina o Iberoamérica. Más precisamente, no hemos podido abordar las tensiones que se manifiestan entre los contextos centrales y periféricos respecto de los fenómenos estudiados.

Finalmente, pero no por ello menos importante, hemos utilizado algunas herramientas del materialismo cognitivo, las vinculadas con los tipos de conocimientos en una perspectiva estática. Pero hemos dejado de lado aquellas asociadas con la dinámica del capitalismo, aquellas que ayudan a comprender la acumulación de capital, mediante los conceptos clave de explotación, expropiación y regulación. Próximas investigaciones deben explorar la potencialidad de la aplicación de esos conceptos al devenir de la discapacidad en el capitalismo informacional. 


\section{Referencias bibliográficas}

Abad, M. et al. (2008). "Apoyo a la integración de estudiantes con discapacidad en la enseñanza universitaria: algunas medidas y propuestas de actuación orientadora". Educación y Diversidad. Revista InterUniversitaria de Investigación sobre Discapacidad e Interculturalidad, 2, pp. 129-150. Recuperado de https://dialnet.unirioja. es/descarga/articulo/2547369.pdf.

Ainscow, M. y Miles, S. (2008). "Por una educación para todos que sea inclusiva: ¿Hacia dónde vamos ahora?”. Perspectivas, 38(1), pp. 17-44.

Anderson, M. y Perrin, A. (7 abril, 2017). Disabled Americans are less likely to use technology [Artículo en un blog] Recuperado de https://www.pewresearch.org/fact-tank/2017/04/07/disabled-americans-are-less-likely-touse-technology/.

Ballejo, G. y Miranda, M. (2004). "Los saberes del poder: La eugenesia y la biotipología en la Argentina del Siglo XX”. Revista de Indias, 64(231), pp. 425-444. Recuperado de http://revistadeindias.revistas.csic.es/index.php/ revistadeindias/article/download/547/614.

Bauman, Z. (2000). Liquid modernity. Cambridge, UK: Polity Press.

Boutang, Y. M. (2011). Cognitive Capitalism. Cambridge: Polity Press.

Bustos, L. et al. (2019). "Discursos de odio: una epidemia que se propaga en la red. Estado de la cuestión sobre el racismo y la xenofobia en las redes sociales". Mediaciones Sociales, 18(1), pp. 25-42. Recuperado de https:// revistas.ucm.es/index.php/MESO/article/download/64527/4564456551208/.

Campos, M. (2015). "Los primeros pasos hacia la enseñanza especial en Costa Rica”. Actualidades Investigativas en Educación, 15(1), pp. 1-28. Recuperado de http://riberdis.cedd.net/handle/11181/4742.

Castells, M. (1996). The Rise of the Network Society. Vol. I of The Information Age: Economy, Society and Culture. Malden, USA; Oxford, UK: Blackwell.

Castoriadis, C. (1997). The Imaginary Institution of Society (Blarney, K). Cambridge, UK: Polity Press (1987).

Cayuela, S. (2017). "Hacia una biopolítica de las discapacidades. La cristalización de un dispositivo en el seno de la gubernamentalidad neoliberal”. EICAISA, Revista de filosofía, (37), pp. 111-137. Recuperado de http:// revistadefilosofia.com/75-06.pdf.

Coleridge, P. (1993). Disability. Liberation and Development. Oxford: Oxfam Publications.

Comité de los Derechos de las Personas con Discapacidad, CDPD (2019). Comité sobre los Derechos de las Personas con Discapacidad. Recuperado de https://www.ohchr.org/SP/HRBodies/CRPD/Pages/CRPDIndex. aspx.

Cuevas, H. (2013). “El gobierno de los sordos: el dispositivo educacional”. Revista de Ciencia Política, 33(3), pp. 693713. Recuperado de https://scielo.conicyt.cl/scielo.php?script=sci_arttext\&pid=S0718-090X2013000300006.

Deleuze, G. (1992). "Postscript on the Societies of Control” October, 59, pp. 3-7.

Dobransky, K. y Hargittai, E. (2016). "Unrealized potential: Exploring the digital disability divide". Poetics, 58(3), pp. 18-28. Recuperado de https://www.zora.uzh.ch/id/eprint/148153/1/DobranskyHargittaiPoetics16DisabilityDividePreprint.pdf. 
Ellcessor, E. (2016). Restricted Access: Media, Disability, and the Politics of Participation. New York: New York University Press.

Ellcessor, E. et al. (2017). Disability media studies. New York: New York University Press.

Ellis, K. y Kent. M. (2011). Disability and New Media. New York and London: Routledge.

Fajardo, S. (2017). "La Educación Superior Inclusiva en Algunos Países de Latinoamérica: Avances, Obstáculos y Retos". Revista Latinoamericana de Educación Inclusiva, 11(1). Recuperado de https://scielo.conicyt.cl/scielo. php?script=sci_arttext\&pid=S0718-73782017000100011.

Feenberg, A. (1991). Critical Theory of Technology. Oxford: Oxford University Press.

Ferrante, C. (2014). "Usos, posibilidades y dificultades del modelo social de la discapacidad". Revista Inclusiones, 1(3), pp. 31-55. Recuperado de https://www.researchgate.net/publication/292145162_Usos_posibilidades_y_ dificultades_del_modelo_social_de_la_discapacidad.

Ferrante, C. (2015). "Políticas de los cuerpos, discapacidad y capitalismo en América Latina. La vigencia de la tragedia médica personal". Revista Inclusiones. Revista de Humanidades y Ciencias Sociales. Año 15, pp. 33-53. Recuperado de https://www.researchgate.net/publication/292145216_Politicas_de_los_cuerpos_ discapacidad_y_capitalismo_en_America_Latina_La_vigencia_de_la_tragedia_medica_personal.

Ferrante, M. (2013). Bibliotecas accesibles para personas con discapacidad visual: Un estudio de caso en la Universidad Nacional de La Plata. [Tesis presentada para la obtención del grado de Licenciada en Bibliotecología y Ciencias de la Información, Universidad Nacional de La Plata]. Recuperado de http://www.memoria.fahce. unlp.edu.ar/tesis/te.820/te.820.pdf.

Ferreira, M. A. V. y Díaz Velázquez, E. (2009). "Discapacidad, exclusión social y tecnologías de la información”. Política y sociedad, 46(1), pp. 237-253. Recuperado de http://revistas.ucm.es/index.php/POSO/article/download/POSO0909130237A/21907.

Foucault, M. (1993). Genealogía del racismo. Buenos Aires: Altamira.

Foucault, M. (2010). The Birth of Biopolitics: Lectures at the Collége de France (Burchill, G.). Houndmills, Hampshire: Palgrave Macmillan (1978-1979).

Fuchs, C. (2010). “Labour in Informational Capitalism. The Information Society”. European Journal of Social Theory, 26(3), pp. 179-196. DOI: https://doi.org/10.1080/01972241003712215.

Goggin, G. y Newell, C. (2003). Digital Disability: The Social Construction of Disability in New Media. Maryland: Rowman \& Littlefield Publishers.

Joly, E. (2007). La discapacidad: una construcción social al servicio de la economía. Recuperado de http://www. rumbos.org.ar/discapacidad-una-construccion-social-al-servicio-de-la-economia-clase-facderuba.

Labrada, E. (2011). “Apropiación tecnológica en personas con discapacidad visual”. Reencuentro, 62, pp. 55-65. Recuperado de https://www.redalyc.org/pdf/340/34021066007.pdf.

López Escribano, C. y Sánchez-Montoya, R. (2012). "Scratch y necesidades educativas especiales: programación para todos". Red. Revista de Educación a Distancia, 34, pp. 1-14. Recuperado de http://revistas.um.es/red/ article/view/233521.

López Mainieri, W. (2012). “Eugenesia y Discapacidad: ¿calidad de vida o genocidio?”. Autonomía Personal, 7 , pp. 36-49. Recuperado de http://autonomiapersonal.imserso.es/InterPresent1/groups/revistas/documents/ binario/rap7afondo.pdf. 
Martín Macías, E. (2010). "La educación especial tras largos siglos de rechazo”. Pedagogía Magna, 5, pp. 71-80. Recuperado de https://dialnet.unirioja.es/descarga/articulo/3391393.pdf.

Martínez Mateus, M. y Rios Rincón, A. (2006). "La tecnología en rehabilitación: Una aproximación conceptual”. Revista Ciencias de la Salud, 4(2), pp. 98-108. Recuperado de https://revistas.urosario.edu.co/index.php/revsalud/article/view/571.

Morales, A. M. (2006). "La era de los implantes cocleares: ¿El fin de la sordera? Algunas consideraciones para su estudio". Sapiens, 7(2), pp. 159-170. Recuperado de http://ve.scielo.org/scielo.php?script=sci_arttext\&pid $=$ S1317-58152006000200011.

Muci-Mendoza, R. (2007). “El accidente de Phineas Gage: su legado a la neurobiología”. Gaceta Médica de Caracas, 115 (1). Recuperado de http://ve.scielo.org/scielo.php?script=sci_arttext\&pid=S0367-47622007000100003.

Naciones Unidas (2006). Convención sobre los Derechos de las Personas con Discapacidad. Nueva York: ONU. Recuperado de https://www.un.org/esa/socdev/enable/documents/tccconvs.pdf.

Organización de los Estados Americanos, OEA (1999). Convención Interamericana para la eliminación de todas las formas de Discriminación contra las Personas con Discapacidad (CIADDIS). Recuperado de https://www.oas. org/juridico/spanish/tratados/a-65.html.

Organización Internacional del Trabajo, OIT (2003). La OIT lanza el primer informe global sobre discriminación en el trabajo. Recuperado de https://www.ilo.org/global/about-the-ilo/newsroom/news/WCMS_071447/lang--es/ index.htm.

Oliver, M. (1990). "Disability and the Rise of Capitalism”. En M. Oliver, The Politics of Disablement (pp. 25-42). London: The MacMillan Press.

Oliver, M. (1998). “¿Una sociología de la discapacidad o una sociología discapacitada?”. En L. Barton (coord.), Discapacidad y sociedad. Madrid: Morata.

Organización de las Naciones Unidas para la Educación, la Ciencia y la Cultura, UNESCO (2018). Education and Disability: Analysis of Data from 49 Countries. Recuperado de http://uis.unesco.org/en/news/education-anddisability-analysis-data-49-countries.

Organización Mundial de la Salud, OMS (2011). Informe Mundial sobre la discapacidad. Malta: OMS. Recuperado de https://www.who.int/disabilities/world_report/2011/summary_es.pdf?ua=1.

Palacios, A. (2008). El modelo social de discapacidad: orígenes, caracterización y plasmación en la Convención Internacional sobre los Derechos de las Personas con Discapacidad. Madrid: Cinda.

Palacios, A. (2010). “¿Por qué el aborto eugenésico basado en discapacidad es contrario a la convención internacional sobre los derechos humanos de las personas con discapacidad?". Revista Síndrome de Down, 27, pp. 50-59.

Palacios, A. y Romañach, J. (2006). El modelo de la diversidad. La Bioética y los Derechos Humanos como herramientas para alcanzar la plena dignidad en la diversidad funcional. Madrid: Diversitás Ediciones.

Paz, C. M. y Salamanca Salucci, M. (2009). "Elementos de la cultura sorda: una base para el currículum intercultural”. REXE. Revista de Estudios y Experiencias en Educación, 8(15), pp. 31-49. Recuperado de http://www. rexe.cl/15/152.htm.

Portales, I. (2004). "Apuntes sobre la evolución histórica de las bibliotecas para personas con discapacidad visual en Cuba". Acimed, 12(4). 
Ragnedda, M. (2017). The third digital divide: A Weberian approach to digital inequalities. Abingdon: Routledge.

Raja, D. S. (2016). Bridging the disability divide through digital technologies. Background Paper for the 2016 World Development Report: Digital Dividends. Nueva York: World Bank. Recuperado de http://pubdocs.worldbank.org/ en/123481461249337484/WDR16-BP-Bridging-the-Disability-Divide-through-Digital-Technology-RAJA.pdf.

Río, M. (2017). "Oftalmología en la historia. La oftalmología en la antigüedad a partir de la edad contemporánea”. Sociedad Cubana de Oftalmología, 30(1). Recuperado de http://scielo.sld.cu/scielo.php?script=sci_arttext\&pi $\mathrm{d}=$ S0864-21762017000100019.

Saussure, F. (2011). Course in General Linguistics (Baskin, W.). New York: Columbia University Press (1916).

Sibilia, P. (2008). La intimidad como espectáculo. Buenos Aires: Fondo de Cultura Económica.

Simón, C. et al. (1995). “El sistema Braille: bases para su enseñanza-aprendizaje”. Comunicación, lenguaje y educación, 28, pp. 91-102. Recuperado de https://dialnet.unirioja.es/descarga/articulo/2941799.pdf.

Soto, M. (2017). "Una evaluación de accesibilidad web a sitios universitarios”. RevCom, 5, pp. 191-205. Recuperado de https://perio.unlp.edu.ar/ojs/index.php/revcom/article/view/4491.

Valencia, L. (2014). Breve historia de las personas con discapacidad: de la opresión a la lucha por sus derechos. Recuperado de http://www.rebelion.org/docs/192745.pdf.

van Dijk, J. A. G. M. (2018). "Afterword: The state of digital divide theory”. En M. Ragnedda y G. Muschert (eds.), Theorizing Digital Divides (pp. 199-206). New York, London: Routledge.

Vercellone, C. (2011). Capitalismo cognitivo. Renta, saber y valor en la época posfordista. Buenos Alres: Prometeo.

Vicente, M. R. y López, A. J. (2010). "A multidimensional analysis of the disability digital divide". Information Society, 26, pp. 48-64. Recuperado de https://www.tandfonline.com/doi/abs/10.1080/01615440903423245.

Villegas, J. (2013). "El Teletrabajo: una forma de inclusión de las personas en situación de discapacidad al mundo laboral y la gestión de sus riesgos laborales”. Revista CES Derecho, 4(1). Recuperado de https://dialnet.unirioja.es/descarga/articulo/4863661.pdf.

Villela, F. y Linares, J. (2011). "Eugenesia. Un análisis histórico y una posible propuesta". Acta Bioethica, 17(2), pp. 189-197. Recuperado de https://scielo.conicyt.cl/scielo.php?script=sci_arttext\&pid=S1726$569 \times 2011000200005$.

von Schrader, S. y Lee, C. G. (2017). Disability Statistics from the Current Population Survey (CPS). Recuperado de https://www.disabilitystatistics.org/.

Williams, R. (1978). Marxism and Literature. Oxford, New York: Oxford University Press.

Winner, L. (1987). La ballena y el reactor: Una búsqueda de los límites en la era de la alta tecnología. Barcelona: Gedisa.

Wittgenstein, L. (1953). Philosophical Investigations (Anscombe, G. E.). Oxford: Blackwell.

Yarza de los Rios, V. A. (2007). "Algunos modos de historiar la educación especial en colombia: una mirada crítica desde la historia de la práctica pedagógica”. Revista Brasilera de Educación Especial, 13(2), pp. 173-188. Recuperado de https://www.scielo.br/scielo.php?pid=S1413-65382007000200003\&script=sci_abstract\&tlng=es.

Yu, H. et al. (2019). "Introduction: disability participation in the digital economy". Information, Communication \& Society, 22(4), pp. 467-473. Recuperado de https://www.tandfonline.com/doi/full/10.1080/136911 8X.2018.1550525. 
Zardel, B. E. (2016). "La constitución o producción de la subjetividad, del sujeto desde el psicoanálisis y del sujetado al discurso de la «discapacidad»". Childhood \& Philosophy, 12(24), pp. 309-341. Recuperado de https:// www.redalyc.org/pdf/5120/512055734006.pdf>.

Zizek, S. (1989). The sublime object of the ideology. London: Verso.

Zukerfeld, M. (2010). "Capitalismo y Conocimiento. Materialismo Cognitivo, Propiedad Intelectual y Capitalismo Informacional." [Tesis doctoral, Facultad Latinoamericana de Ciencias Sociales (FLACSO), Argentina]. Recuperado de https://capitalismoyconocimiento.wordpress.com.

Zukerfeld, M. (2014). "Todo lo que usted quiso saber sobre Internet pero nunca se atrevió a googlear”. Hipertextos, 2(1), pp. 64-103.

Zukerfeld, M. (2017). Anowledge in the Age of Digital Capitalism: An Introduction to Cognitive Materialism. London: University of Westminster Press. 